This item was submitted to Loughborough's Research Repository by the author.

Items in Figshare are protected by copyright, with all rights reserved, unless otherwise indicated.

\title{
The rheological performance of wet-process sprayed mortars
}

PLEASE CITE THE PUBLISHED VERSION

PUBLISHER

(C) Institution of Civil Engineers / Thomas Telford

VERSION

NA (Not Applicable or Unknown)

LICENCE

CC BY-NC-ND 4.0

REPOSITORY RECORD

Austin, Simon A., Peter J. Robins, and Chris I. Goodier. 2019. "The Rheological Performance of Wet-process Sprayed Mortars”. figshare. https://hdl.handle.net/2134/4029. 
This item was submitted to Loughborough's Institutional Repository (https://dspace.lboro.ac.uk/) by the author and is made available under the following Creative Commons Licence conditions.



For the full text of this licence, please go to: http://creativecommons.org/licenses/by-nc-nd/2.5/ 


\title{
THE RHEOLOGICAL PERFORMANCE OF WET-PROCESS SPRAYED MORTARS
}

\author{
S.A.Austin, P.J.Robins and C.I.Goodier \\ Department of Civil and Building Engineering \\ Loughborough University
}

This paper, which reports on part of a three year research project into wet-process sprayed concrete for repair, examines the influence of rheology on the pumping and spraying of mortars. The performance of seven commercially available pre-packaged repair mortars and six laboratory designed fine mortars was examined using the Tattersall two-point and Viskomat rotational viscometers, the pressure bleed test, the slump test, a build test and a vane shear strength test. These tests were used to form a rheological audit of each mortar. The two-point apparatus was successful with low-workability mortars and their flow resistance and torque viscosities were determined. These parameters were also obtained with the Viskomat, although problems were encountered due to their low workability. The pressure bleed test measured both the rate and the total volume of liquid emitted from the mixes whilst the vane shear strength test provided an instantaneous reading of the shear strength of the mortars and is compared with their slump. The mortars were pumped and sprayed through a worm pump to assess their suitability and to measure their adhesion to a substrate by build thickness. This value is a measure of sprayability and is converted into values of maximum shear and bending stress which are then compared with the workability parameters in order to determine their inter-relationship.

\section{Introduction}

Sprayed concrete can be defined as mortar or concrete conveyed through a hose and pneumatically projected at high velocity from a nozzle into place. In the wet-process the constituents (cement, aggregate, admixtures and water) are batched and mixed together before being fed into the delivery equipment or pump. The mix is then conveyed under pressure to the nozzle, where compressed air is injected to project the mix into place. This differs from the dry-process in which the dry constituents are batched together before being conveyed under pressure down the delivery hose to the nozzle, where pressurised water is introduced and the mix projected into place. The rheological properties of 
the mix in the wet process are critical from mixing through to placement (unlike in the dry process where a powder has to be conveyed pneumatically). The concrete's hardened properties are also important, but are of little consequence if the fresh material can not be pumped and placed.

This paper describes the findings of part of a research programme into wet process sprayed concrete for repair, and more specifically the rheological properties of a range of fine mortar mixes, which are defined as mixtures of cement, aggregate with a maximum particle size of 3mm and water, together with any admixtures. The maximum aggregate size of $3 \mathrm{~mm}$ allows the mixes to be conveyed by a worm pump whereas larger aggregate mixes require a piston pump. The mortars tested include seven commercially available pre-packaged concrete repair mortars and six mix designs consisting of combinations of crushed Portland stone, building sand, OPC, silica fume and a styrene butadiene liquid admixture (SBR). Previous work on the rheology of sprayed concrete is discussed, together with the experimental methods used to measure the rheological characteristics of the fine mortars that have been pumped and sprayed. The results of the tests are presented and their relationship to the pumpability and sprayability of the mortars is discussed. The hardened performance of these fine mortars will be described in a subsequent paper

\section{Rheological testing of mortars}

\section{Background}

The wet process can be divided into two stages, pumping and spraying. Thus, a clear understanding of what happens to concrete when it is pumped through a pipeline is fundamental to any study of wetprocess sprayed concrete. Early research into the behaviour of concrete in a pipeline was conducted by Dawson $^{1}$ in 1949. Ede ${ }^{2}$ stated that any saturated combination of solids and liquid has a segregation pressure which is the pressure required to separate liquid and solids, thus transferring pressure from the liquid phase to the solids. He demonstrated that when this occurs the combination of solids and liquid becomes an unpumpable material and the mix therefore needs to have a segregation pressure higher than the pressure required to pass it through the pump and pipeline. In 1962, Gary ${ }^{3}$ developed a "go or no go test", to determine the influence of aggregate grading and shape on pumpability, and he found that for the same slump a concrete may or may not be pumpable. 
Loadwick $^{4}$ established that concrete flows in the form of a solid plug (termed plug flow) separated from the pipe by a lubricating layer consisting of cement, water and fine sand particles. This plug consists of aggregate, sand and cement particles, all separated by a continuous water layer which is hydraulically linked to the water in the lubricating layer. According to hydraulic theory, the distribution of velocity is constant across the width of the plug, with no relative velocity between the aggregate particles. The velocity drops across the lubricating layer to zero at the pipe wall. Browne and Bamforth $^{5}$ showed that it is possible to change from a saturated to an unsaturated state by excessive loss of mix water due to pressure, thus increasing frictional stress, and even blockage. A concrete that dewaters quickly under pressure will be prone to blocking in a pipeline. The pressure bleed test apparatus was thus developed in which a sample of concrete is compressed and the mix water drained to measure the fresh water permeability of a concrete mix, and thus its stability under pressure.

Recent work conducted by Beaupré ${ }^{6}$, has investigated the rheological properties of sprayed concrete and the relationship between pumpability and sprayability, including the development of predictive models based on yield and flow resistance determined from tests conducted with a rotational viscometer. Sprayability can be defined as a property that incorporates parameters such as contact adhesion (ability of plastic mix to adhere to the surface), cohesion (influencing the thickness that can be built-up), and rebound. Beauprè termed this shootability and found a linear relationship between build-up thickness and the yield value of the mix after spraying, and concluded that shootability increases when the flow resistance is increased, and is thus in conflict with pumpability which has the opposite relationship. The research presented here examines further the relationship between build-up thickness, pumpability and shear resistance.

Rheological theory 
Rheology can be defined as 'the science of deformation and flow of matter', and is concerned with the relationships between stress, strain and time. In terms of fresh concrete, the field of rheology is related to the flow properties of concrete and its mobility before setting takes place.

Banfill $^{7}$ reported that cement paste flow curves could be expressed by five different shear/strain models although most authors (Tattersall and Banfill ${ }^{8}$ and Beaupre ${ }^{6}$ ) use the simpler Bingham model as this has been proved to give reasonably accurate and repeatable results within the boundaries of accuracy of the apparatus. For a Bingham plastic the relationship between the shear stress $(\tau)$ and shear rate $(\gamma)$ is given by:

$$
\tau=\tau_{\mathrm{o}}+\mu \cdot \gamma
$$

where $\tau_{\mathrm{o}}$ is the yield stress and at higher stresses there is a linear relationship between $\tau$ and $\gamma$ characterised by the plastic viscosity $\mu$. The resistance to flow of a pumped mortar is influenced by both $\tau_{\underline{o}}$ and $\mu$; strictly speaking the former consists of pressure dependent and non-pressure (absolute) terms.

Mortar can be observed to be a shear thinning liquid in which the viscosity decreases when the shear rate increases. It also possesses a yield value: a minimum shear stress that must be applied before the mortar can begin to flow. This phenomenon is dependent upon both the mixing method and time and therefore both must be controlled in any comparative study, particularly of mortars (concretes are less sensitive due to the shearing action of the aggregate). If this shear thinning effect is permanent then this behaviour is known as irreversible structural breakdown, whereas if the structure reforms after shearing it is said to be thixotropic. This structural breakdown, together with Equation 1 is shown in Figure 1(a).

\section{Rotational viscometer testing}

Tattersall first used a Hobart food mixer to plot flow curves based upon the power needed to drive an impeller in fresh concrete $^{9}$. He later developed a more accurate rheometer with a hydraulic 
transmission, termed the two-point test apparatus (Mk II). Tattersall found that when the torque (T) was plotted against the speed $(\mathrm{N})$ for decreasing results only, the relationship was almost linear (Figure 1(b)):

$$
\mathrm{T}=\mathrm{g}+\mathrm{h} \cdot \mathrm{N}
$$

where $g$ is the intercept on the torque axis and $\mathrm{h}$ the slope of the line. Beaupré ${ }^{6}$ referred to $\mathrm{g}$ as the flow resistance, and $\mathrm{h}$ as the torque viscosity. This equation is of the same form as the Bingham model (Equation 1) and thus it can be said that $g$ is a measure of yield value, and $\mathrm{h}$ of plastic viscosity. The principle is the same for the Viskomat ${ }^{10}$ rotational viscometer, a commercially available instrument capable of producing flow curves for mortar. Approximately $0.9 \mathrm{Kg}$ of mortar is placed into a cylindrical container mounted on a variable-speed rotating turntable and a concentric paddle is inserted into the mortar which is then subjected to a pre-programmed speed and temperature program. All the readings for paddle torque, speed, temperature and time are continuously recorded by the computer as the test progresses and on completion the results can be displayed and printed either graphically or numerically. Flow curves in the form of the Bingham model can then be automatically produced. In principle it is possible to convert $\mathrm{g}$ and $\mathrm{h}$ to fundamental units equivalent to $\tau_{\mathrm{o}}$ and $\mu$ by calibration with standard fluids (Banfill') but most investigations work with the direct parameters (which are equipment dependent).

\section{Materials and mortar mixes}

The research has investigated seven proprietary repair mixes (mainly designed for hand application) and six designed mixes. For the latter, the ordinary Portland cement conformed to BS12:198911 and the silica fume was a proprietary undensified powder. The sands were a crushed Portland stone sieved to a maximum size of $3 \mathrm{~mm}$ and a building sand graded between $\underline{75 \mu \mathrm{m}}$ and $2.36 \mathrm{~mm}$. Some mixes also included an SBR in a 3:1 water:SBR suspension.

There are several hundred commercially available concrete repair systems and Emberson and Mays ${ }^{12}$ categorised these into nine generic types. Of these, two of the most widely used are the SBR-modified 
cementitious and OPC/sand mortar types. Commercial considerations prevent the publication of the formulations of these pre-packaged mortars, but they typically contain all or most of the following constituents, depending on the type:

(i) a combination of fine aggregates from $\underline{75 \mu \mathrm{m}}$ to $2 \mathrm{~mm}$ in diameter;

(ii) lightweight fillers, $75 \mu \mathrm{m}$ to $300 \mu \mathrm{m}$ in diameter;

(iii) OPC in approximately the ratio of 3:1;

(iv) silica fume (approximately $5 \%$ of the OPC);

(v) admixtures such as SBR;

(vi) polypropylene fibres up to $6 \mathrm{~mm}$ in length; and

(vii) chemical shrinkage compensators.

The overall gradings (of both the aggregate and cementitious components) of all the mixes are shown in Table 1, the proportions of the mixes designed for the project in Table 2 and the constituents of the pre-packaged mortars in Table 3.

The mortars were mixed using a $0.043 \mathrm{~m}^{3}$ capacity forced action paddle mixer. The pre-packaged mortars were mixed according to the manufacturers instructions with 3.3 to 4.0 litres of water per 25Kg bag of dry material and a mixing time of approximately 4 minutes. The designed mixes were mixed in the same way and in all cases the water was added until the desired consistency for spraying was achieved. i.e. workable enough to be pumped but stiff enough not to slough after being sprayed onto a vertical substrate. The mortar was pumped through a Putzmeister TS3EVR ${ }^{13}$ variable speed worm pump and then down a $25 \mathrm{~mm}$ diameter rubber hose at an approximate rate of $6 \mathrm{l} / \mathrm{min}$. The mortar was then sprayed with an air pressure of approximately $300 \mathrm{kPa}$.

\section{Testing procedure}

Results for six rheological tests are presented, two for workability, three for pumpability and one for sprayability. The test methods are described briefly below and, taken in this order, they enable a 
rheological audit to be made of a mix as it progresses through the mixing, pumping and spraying process, as shown in Figure 2.

\section{Workability}

The workability was measured by the slump test ${ }^{14}$ and by a modified form of the shear vane test for soils ${ }^{15}$. Two slumps were measured immediately after the mortar had been mixed and if these slumps were significantly different $(>15 \mathrm{~mm})$ then a third was taken and the average of the two closest values calculated. The shear vane test was investigated as a simple, portable apparatus which could give an indication of the workability of a mortar at various points in the pumping and spraying process. It consists of a torque measuring device at the head of the instrument together with a set of vanes to provide sufficient shear resistance to register on the torque scale. The maximum torque can then be used to calculate a shear strength for the mortar (in $\mathrm{kPa}$.).

\section{Pumpability}

Two rotational viscometers (Tattersall two-point and the Viskomat) and a pressure bleed test were used to characterise pumpability. The two-point apparatus was the Mk II version developed by Tattersall ${ }^{9}$ which has been found to be satisfactory for medium- to high-workability concretes. The mortars tested here had slumps of between 45 and $80 \mathrm{~mm}$ and it has been suggested that the apparatus might not be sensitive enough for mortars if the torques exerted on the impeller are too low to give a significant increase in pressure ${ }^{9}$, but sufficient change was observed in this work.

During preliminary trials with the two-point apparatus empty it was found that the recorded pressure at a constant speed decreased over time. The apparatus was therefore always warmed up prior to testing for a period of 2 hours at a speed of 0.9 rev/s, after which the change in recorded pressure with time was negligible. The idling pressures were then recorded between the speeds of 0.6 and $2.6 \mathrm{rev} / \mathrm{s}$ at increments of $0.2 \mathrm{rev} / \mathrm{s}$. With the bowl rotating at $0.6 \mathrm{rev} / \mathrm{s}$ the bowl was gradually filled with approximately $25 \mathrm{Kg}$ of mortar to a level $75 \mathrm{~mm}$ below the top of the bowl. The speed was then increased in increments of $0.2 \mathrm{rev} / \mathrm{s}$ and the corresponding pressures recorded. Once $2.6 \mathrm{rev} / \mathrm{s}$ had been reached the speed was reduced incrementally in the same way and the corresponding pressures again 
recorded. The decreasing results that follow the structural breakdown (Figure 1(b)) were used for calculating g and h.

Mortars for testing in the Viskomat were mixed in a variable-speed food mixer with a planetary motion at a speed of $110 \mathrm{rev} / \mathrm{min}$ for 60 seconds, then at $210 \mathrm{rev} / \mathrm{min}$ for a further 90 seconds. The mortar was then transferred into the temperature controlled container on the Viskomat and the measuring paddle was lowered into it. The rheology of Bingham plastics is not very sensitive to temperature, but the rate of change of rheology with time in a chemically reacting cementitious material is ${ }^{7}$, therefore both the test temperature and the time after mixing at which the test was started were standardised at $20 \pm 2^{\circ} \mathrm{C}$ and 5 minutes respectively (these values being chosen after preliminary testing).

The pressure bleed apparatus ${ }^{5}$, consisted of a $125 \mathrm{~mm}$ diameter steel cylinder with a detachable cap and base, the former locating an O-ringed piston within the top of the cylinder. The inside of the base was lined with a $75 \mu \mathrm{mm}$ mesh and a bleed hole with a stop tap was located beneath the mesh. The cylinder was filled with approximately $1700 \mathrm{~cm}^{3}$ of mortar which was lightly tamped and then the top cap and piston were put in position. The apparatus was placed in a $100 \mathrm{kN}$ Instron compression testing machine and then the sample was subjected to a load of $12.2 \mathrm{kN}$, equivalent to 10 bar (1000 kPa.), which was the highest pumping pressure recorded with the TS3EVR worm pump. The valve was opened after 10 seconds and the liquid (consisting of water, cement and silica fume particles and possibly SBR) squeezed from the sample was collected in a beaker on a digital balance. Both time and weight were data-logged for 30 minutes, from which a curve of liquid emitted against time elapsed was produced. The time needed to expel the liquid is heavily dependant upon the liquid-cement ratio and on the mix grading and composition.

\section{Sprayability}

This was assessed both qualitatively (did the material pass through the nozzle) and quantitatively (in terms of the amount of material that could be built up on a standard grit-blasted $500 \times 500 \times 50 \mathrm{~mm}$ concrete substrate (with mix proportions of $1: 2.3: 2.3$ and a w/c ratio of 0.48 )). The mortar was sprayed horizontally onto a 300x300mm target area to try and obtain as large an amount of material as 
possible on the substrate whilst keeping within the 'target'. The mortar would then fail under its own weight either cohesively, adhesively or a combination of both. The total weight of mortar was then recorded, together with the failure mode and the maximum depth of build.

\section{Test results}

\section{Shear vane}

The shear vane provides a basic measure of the shear strength (in $\mathrm{kPa}$ ) of a mortar and this is plotted against slump (in mm), as shown in Figure 3. As would be expected, this shows a decrease in shear strength for an increase in slump. The shear vane test can provide an instantaneous result exactly where the rheological properties of the mortar needs to be measured, e.g. in the hopper of the pump. The shear strength has been calculated using the British Standard formulas for the measurement of soil shear strength ${ }^{15}$ multiplied by a conversion factor for the increased vane size.

\section{Tattersall two-point test}

Figure 4(a) shows the results obtained from the two-point test on the mix P1. They show a distinct upcurve and downcurve which was typical for all the mortars tested. However, approximately half way along the downcurve the torque appears to increase as the impeller speed decreases. This is due to the mortar not falling into the impeller sufficiently and therefore not creating a high enough reading above the idling pressures. A regression line drawn through these points, as shown in Figure 4(a) provides misleading values of $g$ and $h$. The points from the initial part of the downcurve (Figure 4(b)) have therefore been used in this paper for plotting the downcurve, and hence calculating $\mathrm{g}$ and $\mathrm{h}$.

The values of $g$ and $h$ for the mix D1 at different slumps are shown in Figure 5(a). The trend, as would be expected, is for the yield value and plastic viscosity to increase as the slump decreases (the exception being the 50mm slump $\mathrm{h}$ value of 0.40 , the apparatus being at the limit of its reliable range at

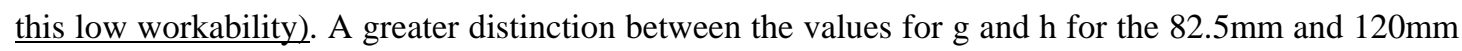
slumps would be expected but these results suggest that the apparatus is less sensitive for mortars at higher slumps. Figure 5(b) shows the g and h for the mortar P2 after it has been mixed, pumped or 
sprayed. The increase in both $\mathrm{g}$ and $\mathrm{h}$ as the mortar is pumped and then sprayed would be expected as the excess air is forced out of the mortar.

The two-point test results for all the mortars in this study are shown in Figures 6(a) and 6(b). They were all mixed with water prior to testing until the desired consistency for pumping and spraying had been achieved. The pre-packaged mortar with both the highest g and highest h was mix P1 which had the most 'basic' mix design of all the pre-packaged mortars tested, and contained no polymers, fibres or lightweight fillers. The mix with the next highest value of $\mathrm{g}, \mathrm{P} 4$, also had a relatively basic mix design and together they were the cheapest commercially of all the pre-packaged mortars that were tested. The two highly polymer-modified mixes(P6 and P3) had the lowest values of g, although their corresponding values of h were very different. The mix P3 is a two-part (powder and liquid) reprofiling mortar which had been formulated to enable it to be applied in thin layers without it separating or being too 'sticky', which could explain why it had the smallest value of g. The designed mixes in Figure 6(b) show a clear trend dependent upon the mix design: the greater the proportion of crushed Portland stone within the mix compared with the building sand then the greater the value of $\mathrm{g}$. The addition of SBR to a mix, in this case mix D5 having no SBR and mix D1 being an identical mix containing a 3:1 water:SBR solution, appears to have little effect on either $\mathrm{g}$ or h. This is in contrast with the pre-packaged mortars where the highly polymer-modified mortars possessed a lower value of g.

\section{Viskomat rotational viscometer}

Existing data published on the Viskomat ${ }^{7,10,16}$ is on mortars with a workability higher than those in this study and several different measurement profiles of speed against time are documented. A standard profile had to be chosen for this study and mix D1 was tested in the Viskomat at speeds of 200, 180, 160 and $140 \mathrm{rpm}$ for 20 minutes at a stiffness at which it would be sprayed. The changes in torque against time for these different speeds are shown in Figure 7. The tests conducted at 180 and $200 \mathrm{rpm}$ experienced structural breakdown for approximately seven and eight minutes respectively. The tests conducted at 140 and $160 \mathrm{rpm}$ also demonstrated structural breakdown for up to two minutes but this breakdown was significantly smaller than for the higher speeds and so a speed of $200 \mathrm{rpm}$ for a time of 
10 minutes was chosen for the structural breakdown duration of the testing profile. The remainder of the profile consisted of decreasing steps of 20 rpm every 2 minutes down to a minimum speed of 60 rpm, as at lower speeds the mortar ceased rotating with the pot. Figure 8(a) shows the torque against time graph for mix P4 using breakdown speeds of 180, 160, 140 and $120 \mathrm{rpm}$ and it can be seen that decreasing the breakdown speed decreases the value of h. The values recorded at the speeds of 160 and $180 \mathrm{rpm}$ have been excluded as their recorded torques increased as their speeds decreased due to the mortar rotating with the pot occasionally at high speeds. This was the main problem encountered when testing low workability mortars with the Viskomat.

The pre-packaged mortars P1, P2, P4, P6 and P7 are shown in Figure 8(b). Due to some of the mortars not flowing sufficiently, a profile was used that increased the initial speed in increments, with one minute at $50 \mathrm{rpm}$, one minute at $100 \mathrm{rpm}$, one minute at $150 \mathrm{rpm}$ and then finally 10 minutes at 200 rpm (for the breakdown period). The speed then decreased in steps of 20 rpm every 2 minutes as before. The mortar P1 was initially tested at the stiffness used for spraying, but it would not breakdown at any of the breakdown speeds or rotate sufficiently with the pot. It was therefore tested at a higher workability than would typically be used for spraying, which explains why this produced the lowest value for $g$ of all the mortars tested. This mortar was also the most difficult to pump of the prepackaged mortars tested and it was the only polymer-free pre-packaged mix tested.

Mortar P2 broke down quickly and produced the highest value for g. Mortars P4 and P7 broke down but began to trap air within the sample after 17 and 13 minutes respectively causing the mortar to rise within the pot and so these tests were ended prematurely. These two mortars had the lowest values for $\mathrm{h}$ of the pre-packaged mortars tested which agrees with the work of Beaupre ${ }^{6}$, who reported that $\mathrm{h}$ decreases with the addition of air entrainment, although the opposite effect has also been reported by Wolter $^{16}$. The mortar with the next lowest value of h, P1, had the highest workability which is consistent with the low values of both h and g. Another problem encountered with mortars P4, P7 and P6 was that the polypropylene fibres became trapped around the paddle and the scraper within the pot, which increases the torque on the paddle due to the enlarged surface area. This also alters the mix proportions of the mortar as the fibres have effectively been 'removed' from the mix. Mix P4 also took 
the longest to break down (with the exception of P1), the mortar not beginning to flow until a speed of 100 rpm. The final mix, P6, broke down easily and did not trap any air.

Figures 9(a) and (b) compare the values obtained with the Two-point test and the Viskomat. The apparatus and the units are different and so direct comparisons of the numerical results for each mortar can not be made. As mentioned earlier, the values for P1 of both $g$ and $h$ are significantly lower when using the Viskomat due to the higher workability of the mix than when tested in the Two-point. This mix did produce the highest value of g with the Two-point test which suggests that this material may have a yield value at this water content which is too high for testing in the Viskomat. The material that produced the next highest value of g with the Two-point test, $\mathrm{P} 4$, was also the second most difficult to break down with the Viskomat. Figure 9(b) shows that the two mixes with the lowest values for $\mathrm{h}$ in the Viskomat (P4 and P7) trapped the air during the test although the corresponding values for g do not seem to have been affected. This Figure also shows that mixes P2 and P6, which broke down quickly in the Viskomat, have relatively higher values of h, compared with the other materials, in the Viskomat than in the Two-point.

Comparing the two tests, the Two-point was more effective at the low workabilities used for spraying as it was difficult to break down the mortars sufficiently in the Viskomat and the basic mixes containing no polymers (such as P1) could not be tested in the latter. The polymer-modified mortars (such as P2 and P6) could be tested effectively in the Viskomat although some of these mortars (P4 and P7) trapped air during testing.

\section{Pressure bleed test}

Figure 10(a) shows that the total liquid emitted from the pre-packaged repair mortars in the first 30 minutes ranged from 20 to 140ml. This liquid was a combination of water, SBR, OPC, silica fume and very fine $(<75 \mu \mathrm{m})$ sand particles. The relatively basic mortars (P1 and P4) that contain little or no polymers emitted the largest total amount of liquid at the fastest rate and the highly polymer-modified mixes (P6 and P7) emitted a smaller total amount of liquid at a slower rate. The two-part re-profiling mortar (P3) emitted a small amount of liquid (20ml) very quickly in the first 2.5 minutes but then the 
rate of bleeding decreased rapidly. As stated in section 4, the resistance of a mix to bleeding is dependant upon the mix composition, especially the grading of the constituents. Comparing the gradings of the mixes in Table 1 with Figure 10(a) it can be seen that the mixes with the lowest proportion of fine material emitted the most liquid and vice versa. The smoothness of the grading is also important as any gaps in the grading allow the liquid and the fine particles to flow through.

Figure 10(b) shows that the total amount of water emitted from the designed mixes ranges from 45 to 120ml. The mixes containing no SBR (D5 and D6) emitted a larger volume of liquid at a much higher rate than the mixes with SBR. As mentioned previously, mix D5 is identical to mix D1 except that the latter contained SBR. Mixes D1 to D4 contained varying proportions of crushed stone and building sand as shown in Table 2. The mix with the most fines (D1) emitted the most liquid at the quickest rate and the mix with the least fines (D4) emitted the least liquid at the slowest rate. This is due to the higher water content needed when a greater proportion of fines are present in order to obtain the same workability.

\section{Build test}

The build value (in mm) and corresponding mass of mortar for each of the mixes are shown in Table 4. The shear stress at failure was then calculated from the cross-sectional area at the base of the mortar (approximately 300mm square). The tensile stress due to bending was also calculated by idealising the mortar on the substrate into the frustum of a square-based pyramid. The volume, and therefore the dimensions of this frustum, could be calculated using the mass, the fresh wet density, the area of the base and the height of the frustum (i.e. the build value). This shape was then used to calculate the moment and hence the maximum tensile bending stress of the mortar.

Figure 11(a) shows the relationship between the slump of the mortar before pumping and the maximum tensile and shear stresses at failure which indicates an increase in both stresses for an increase of slump. This seems the reverse of what would be expected but at the low workabilities tested here, an increase in slump would produce a slightly wetter, and therefore more cohesive mix, thereby increasing the build. This behaviour is shown graphically in Figure 11(b). As the slump increases from 
zero there is initially no increase in build as the material is too dry to adhere to the substrate. As the slump increases further the mix becomes more cohesive and the build increases (as seen here) until it reaches a maximum point at which the mix possesses both it's maximum tensile and maximum shear (flow) strength. Past this point the mix begins to fail in shear as the slump, and hence the fluidity, increases. A maximum slump is then reached at which point the mix is too fluid to adhere to the substrate and the build is therefore zero.

Beaupré also reported that an increase in the value for g (the flow resistance, obtained from the Twopoint test) produced a corresponding increase in the build value. The relationship between these two parameters in this study is shown in Figure 12 although the trend is not as strong as that found by Beaupré (who tested 10mm aggregate sprayed concretes with build values from 10 to $350 \mathrm{~mm}$ compared to the 3mm maximum aggregate mortars presented here which have build values between 200 and $300 \mathrm{~mm})$.

Figure 13(a) presents the relationship between the vane shear strength immediately before pumping and the maximum tensile and shear stresses at failure. These results indicate an increase in the failure stresses for a decrease in vane shear strength. As in Figure 11(a), this seems the opposite relationship to what would be expected but at these low workabilities a decrease in shear strength could produce an increase in the cohesiveness of the mortar, and therefore a corresponding increase in the maximum failure stress. As the vane shear strength decreases further (due to an increase in workability) a point is reached where the mortar no longer fails due to the tensile stresses being exceeded but by a shear (i.e. flow) failure (see Figure 13(b)). At this point the maximum build is obtained, although this point was difficult to establish here due to the narrow range of workabilities.

\section{Conclusions}

This paper has presented and discussed a variety of data on the rheological performance of wet-sprayed fine mortars. A rheological audit has been developed and tests for each stage within this audit have been used to characterise the pumpability and sprayability of each mortar. A shear vane test has been 
developed which can give an instantaneous measurement of the shear strength of the mortar wherever this property needs to be assessed and a good correlation with the slump of a mortar has been found.

The Two-point test apparatus produced satisfactory results with fine mortars with low workabilities, although care needed to be taken in both conducting the test and interpreting the results. Both the grading of the constituents and the presence of polymers had a significant effect on the flow resistance and torque viscosity. A procedure was developed for the Viskomat apparatus but the results obtained from the pre-packaged mortars were inconclusive, with difficulties being encountered due to their low workability and the tendency of some mixes to entrain air or trap polypropylene fibres around the measuring paddle.

The pressure bleed test demonstrated that the presence of an SBR significantly influences both the rate and total emission of liquid from the mix under pressure. The proportion of fine material and the water content of the mix were also crucial factors in the amount and rate of liquid emitted.

The results of pumping and spraying trials on different mortars have been presented together with the associated values for slump, build and vane shear strength and a relationship has been found that links together these three parameters. A new method that defines the build in terms of the maximum shear and tensile bending stresses generated at failure has been outlined which enables a more detailed and scientific analysis of the sprayability of the mortar to be made and a relationship between these stresses, the slump and the vane shear stress of the mortars has been found.

\section{Acknowledgements}

The authors are grateful for: the financial support of the EPSRC (Grant number GR/K52829); the assistance of the industrial collaborators Balvac Whitley Moran, Fibre Technology, Fosroc International, Gunform International Ltd and Putzmeister UK Ltd; and the supply of additional materials by CMS Pozament, Flexcrete Ltd and Ronacrete Ltd.

\section{References}


1. DAWSON, O. Pumping concrete - friction between concrete and pipeline. Magazine of Concrete Research, 1949, 1, 3, pp. 135-146.

2. EDE, A.N. The resistance of concrete pumped through pipelines. Magazine of Concrete Research, November 1957, pp. 129-140.

3. GARY, J.E. Laboratory procedure for comparing the pumpability of concrete mixtures. Proceedings ASTM, 1962, vol. 62, pp. 129-140.

4. LOADWICK, F. Some factors affecting the flow of concrete through pipelines. Proceedings of 1st Int. Conf. Hydraulic Transport of Solids in Pipes, 1970. British Hydromechanics Research Association, Bedford, UK.

5. BROWNE, R.D. AND BAMFORTH, P.B. Tests to establish concrete pumpability. ACI Journal, May 1977, pp. 193-203.

6. BEAUPRÉ, D. Rheology of high performance shotcrete. PhD Thesis, University of British Colombia, February 1994.

7. BANFILL, P.F.G. Rheological methods for assessing the flow properties of mortar and related materials. Construction and Building Materials, 1994, Vol. 8, No. 1, pp. 43-50.

8. TATTERSALL, G.H. AND BANFILL P.F.G. The rheology of fresh concrete. Pitman books Ltd, London, 1983.

9. TATTERSALL, G.H. Workability and Quality Control of Concrete. E\&FN Spon, London, 1991, pp. 57.

10. SCHLEIBINGER GERÄTE, Haager Strasse 2, 8255 Schwindegg, Germany.

11. BRITISH STANDARDS INSTITUTION. Specification for Portland cements. BS12:1989, British Standards Institution, London.

12. EMBERSON, M.K. AND MAYS, G.C. Significance of property mismatch in the patch repair of structural concrete, Part 1, Properties of repair system. Magazine of Concrete Research, 1990, 42(152), pp. 147-160.

13. PUTZMEISTER LTD., Carrwood Road, Chesterfield Trading Estate, Sheepbridge, Chesterfield, Derbyshire, S419QB.

14.BRITISH STANDARDS INSTITUTION, Method for determination of slump, BS1881:Part102:1983, British Standards Institution, London. 
15. BRITISH STANDARDS INSTITUTION. Specification for soils for civil engineering purposes, Part 9. In-situ tests, BS 1377:Part 9:1990, British Standards Institution, London.

16. WOLTER, H. Measuring Flow Properties of New Concrete Mixes, “Holderbank” News, 1990, 12, pp. 50-52. 


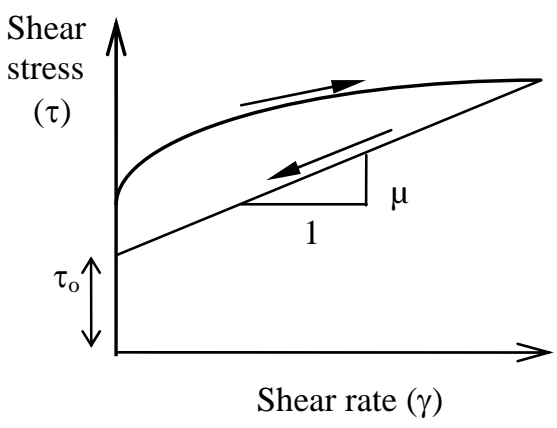

(a) Stress-strain



(b) Torque-speed

Figure 1. Typical flow curve for mortars.

\begin{tabular}{|c|c|c|c|c|c|}
\hline & \multicolumn{5}{|c|}{ Stage in pumping/spraying process } \\
\hline & Mixer & Pump & Hose & Stream & In-situ \\
\hline Shear rate & High & Low-medium & $\begin{array}{l}\text { Zero (Plug } \\
\text { flow) }\end{array}$ & Zero & Zero \\
\hline Pressure & Atmospheric & Atmospheric & $\begin{array}{c}\text { High (10bar) } \\
\text { - Reducing } \\
\text { to zero }\end{array}$ & Atmos. & Atmos. \\
\hline \multirow{4}{*}{$\begin{array}{r}\text { Possible } \\
\text { rheological } \\
\text { tests }\end{array}$} & \multicolumn{2}{|c|}{ Tattersall two-point } & \multirow{4}{*}{ Pressure bleed } & & \multirow{4}{*}{ Build } \\
\hline & \multicolumn{2}{|c|}{ Viskomat viscometer } & & & \\
\hline & \multicolumn{2}{|c|}{ Slump } & & & \\
\hline & \multicolumn{2}{|c|}{ Shear Vane } & & & \\
\hline
\end{tabular}

Figure 2. Rheological audit. 


\begin{tabular}{c|ccccccc|ccccc}
\hline & \multicolumn{7}{|c|}{ Pre-packaged repair mortars } & \multicolumn{5}{c}{ Designed mixes } \\
\hline $\begin{array}{l}\text { Sieve } \\
\text { size: } \mathbf{~ m m ~}\end{array}$ & P1 & P2 & P3 & P4 & P5 & P6 & P7 & D1 & D2 & D3 & D4 & D5 \\
\hline $\mathbf{1 . 7}$ & 100 & 100 & 100 & 100 & 100 & 100 & 100 & 98 & 99 & 99 & 99 & 98 \\
$\mathbf{1 . 1 8}$ & 98 & 100 & 100 & 100 & 91 & 100 & 100 & 94 & 96 & 97 & 98 & 94 \\
$\mathbf{0 . 8 5}$ & 83 & 99 & 100 & 97 & 87 & 100 & 96 & 90 & 92 & 94 & 96 & 90 \\
$\mathbf{0 . 6}$ & 79 & 91 & 99 & 83 & 84 & 80 & 90 & 84 & 86 & 88 & 90 & 84 \\
$\mathbf{0 . 4 2 5}$ & 58 & 84 & 89 & 63 & 66 & 77 & 88 & 75 & 74 & 74 & 74 & 75 \\
$\mathbf{0 . 3}$ & 51 & 70 & 77 & 50 & 58 & 67 & 80 & 66 & 60 & 54 & 49 & 66 \\
$\mathbf{0 . 1 5}$ & 41 & 43 & 67 & 34 & 51 & 45 & & 49 & 42 & 35 & 27 & 49 \\
\hline
\end{tabular}

Table 1. Combined gradings of all mixes (percentage passing).

\begin{tabular}{ccccccc}
\hline Mix & $\begin{array}{c}\text { Crushed } \\
\text { stone }\end{array}$ & $\begin{array}{c}\text { Building } \\
\text { sand }\end{array}$ & OPC & $\begin{array}{c}\text { Silica } \\
\text { fume }\end{array}$ & SBR:Water & $\begin{array}{c}\text { Liquid/cement- } \\
\text { itious ratio }\end{array}$ \\
\hline D1 & 3 & 0 & 1 & 0.05 & $1: 3$ & 0.65 \\
D2 & 2 & 1 & 1 & 0.05 & $1: 3$ & 0.55 \\
D3 & 1 & 2 & 1 & 0.05 & $1: 3$ & 0.48 \\
D4 & 0 & 3 & 1 & 0.05 & $1: 3$ & 0.44 \\
D5 & 3 & 0 & 1 & 0.05 & $0: 3$ & -- \\
D6 & 4 & 0 & 1 & 0.05 & $0: 3$ & - \\
\hline
\end{tabular}

Table 2. Proportions of designed mixes (by weight).

\begin{tabular}{cccccl}
\hline Mix & Polymer & Fibres & Shrinkage & $\begin{array}{c}\text { Lightweigh } \\
\text { t } \\
\text { modified }\end{array}$ & \multicolumn{3}{c}{ ( } & comp. & Mortar description & \\
\hline P1 & No & No & Small amount & No & Basic general-purpose repair mortar \\
P2 & Yes & Yes & Yes & Yes & High build repair mortar \\
P3 & Yes & Yes & Yes & Yes & 2-part re-profiling for wet-spraying \\
P4 & Yes & Yes & No & Yes & Basic repair mortar for wet spraying \\
P5 & Yes & Yes & No & Yes & Render/repair mortar \\
P6 & Yes & Yes & Yes & Some & Repair mortar \\
P7 & Yes & Yes & Yes & Yes & Lightweight repair mortar \\
\hline
\end{tabular}

Table 3. Composition of pre-packaged mortars.

\begin{tabular}{cccccc}
\hline Mix & $\begin{array}{c}\text { Build } \\
(\mathbf{m m})\end{array}$ & $\begin{array}{c}\text { Mass } \\
\mathbf{( k g )}\end{array}$ & $\begin{array}{c}\text { Max. shear } \\
(\mathbf{k N / m})\end{array}$ & $\begin{array}{c}\text { Bending stress } \\
(\mathbf{k N} / \mathbf{m} \mathbf{)})\end{array}$ & Failure mode \\
\hline D1 & 210 & 21.4 & 2.6 & 2.1 & Adhesive \\
D2 & 300 & 27.3 & 3.3 & 4.9 & Cohesive \\
D3 & 280 & 24.2 & 2.9 & 3.9 & Adhesive \\
D5 & 270 & 26.8 & 3.2 & 3.5 & Cohesive \\
D6 & 220 & 23.2 & 2.8 & 2.4 & Adhesive \\
\hline P1 & 320 & 41.5 & 3.8 & 3.5 & Cohesive \\
P2 & 270 & 13.0 & 3.1 & 3.0 & Cohesive \\
P3 & 230 & ---- & 2.3 & 2.4 & Adhesive \\
P4 & 290 & 26.6 & 3.7 & 3.7 & \\
P5 & 300 & 49.5 & 5.9 & 4.4 & \\
P6 & 200 & 32.2 & 3.9 & 1.6 & \\
P7 & 350 & ---- & 2.5 & 3.9 & \\
\hline
\end{tabular}

Table 4. Build test results. 